\title{
Construction of Internet plus College Based on the Ecological Circle of Industry and Education
}

\author{
Jianfeng HU \\ Jiangxi University of Technology, 330098 Nanchang, China \\ huguess@qq.com
}

Keyword: Internet plus; Creative Education; Integration of industry and education

\begin{abstract}
Integration of industry and education can promote the application talents training. To further promote the reform of talents training mode, cultivating students' creative ability, school implement ten initiatives to enhance the student's ability of innovation and entrepreneurship. The arrival of the Internet plus era is triggering the competition and reform of higher education pattern in the world. Construction of Internet plus college can realize training application talents and innovation talents.
\end{abstract}

\section{Integration of industry and education}

The basic connotation of the integration of industry and education is the depth interaction between enterprise and the school, which put school education, teaching process with the industries and enterprises, labor, cultivate quality, skills upgrading, research and development of science and technology, management and social service in one. The development of the depth fusion type break down barriers between occupation and education, enterprise and school, work and learning, which form a community of "win-win cooperation", forming a "win-win" situation of benign interaction between industry and education. Integration of industry and education not only promote the application talents training, but also promote the joint between school and enterprise to carry out technology research, so as to promote enterprise technology progress, industrial restructuring and upgrading and regional economic and social development. The basic requirements of the integration of industry and education is to achieve the five docking. First, major settings are docking industry needs. Two is the course content docking occupation standard. Three is the teaching process docking the production process. Four is the graduation certificate docking vocational qualification certificate docking. Five is the vocational education docking lifelong learning.

\section{Creative Education}

To further promote the reform of talents training mode, cultivating students' creative ability, school implement ten initiatives to enhance the student's ability of innovation and entrepreneurship. Firstly, to innovate education idea. School pays attention to the education and the guide of innovation spirit, puts forward innovation education idea into campus culture and whole education process. Second, to implement responsibility system of creative education. Third, to establish Innovation Institute, which is not only responsible for the guidance of creative and entrepreneurship education, and bear the practice of creative and entrepreneurship training. Fourth, to construct 
creative classes. School build a variety of creative classes and groups, in order to encourage students to participate in innovative activities. Fifth, to select tutor for creative education. School guide the students' innovative activities as an important content of the assessment to guide teacher's work load, and construct the base of innovation mentor. Sixth, to encourage intellectual property, school takes the declaration of the patent as the embodiment of an important starting point for the innovation. Seventh, to make full use of platform effect of the University Science and Technology Park, and provide platform support and guidance for students creative and entrepreneurship. Eighth, to build innovative practice base for cultivating students' innovation ability. School let students participate in the innovation practice and technological practice in the process of enhancing the innovation consciousness, innovation ability, cultivating the spirit of innovation and widely played its demonstration role in students' science and technology activities, and strive to create a good atmosphere for innovation. Ninth, to strengthen the creative and entrepreneurship education platform construction, set up the base for students creative and entrepreneurship education, the base for intellectual property education, the base for innovative approaches training and innovative studio. Tenth, to introduce incentive system for creative education, school establishes the performance evaluation system for students' innovative mentor and students, establish students innovative entrepreneurial activity funds and special scholarship.

\section{Internet plus}

Along with the transition of the industry society into the information society, internationalization and informationization have become the inevitable trend of higher education development. In particular, the arrival of the Internet plus era, and the wide rise of the multiple online open courses (MOOCs) in recent years, are triggering the competition and reform of higher education pattern in the world. Under this background, the development mode of higher education is comprehensively transformation. Internet plus era, information technology has penetrated into all aspects of economic development and social life, people's mode of production, way of life and ways of learning is taking place profound changes, universal education, quality education, lifelong learning and individualized learning has become an important feature of the development of education in the information age. Internet plus traditional major will be the birth of a new major or course, such as Internet plus marketing is the electronic commerce, Internet plus art is the online art, Internet plus software is the app development, Internet plus hardware is Internet of things, Internet plus trade is etrade.

\section{Basic principles of the formation of the Internet plus College}

$\mathbf{N}$ corresponds to $\mathbf{N}$. Just like shown in Fig. 1, the maximum difference between internet plus college and traditional college is $\mathrm{N}$ corresponding to $\mathrm{N}$, that is to say, school is not only for a certain industry, a certain enterprise, a certain position, company is not only for a major, some of the courses. Internet plus college highlight mix and fusion, put school and society as an organic fusion together, put major and enterprise fusion together, put position and course fusion together. Enterprise move to school, the school build enterprise. $\mathrm{N}$ corresponding to $\mathrm{N}$ has the following form: (1) Multiple industries corresponds to multiple colleges; (2) Multiple enterprises corresponds to multiple majors; (3) Multiple positions corresponds to multiple classes; (4) Multiple working contents corresponds to multiple teaching contents; (5) Multiple working ways corresponds to multiple teaching methods; (6) Multiple job assessment corresponds to multiple teaching assessment; (7) Multiple working scenes 
corresponds to multiple teaching modules; (8) Multiple working plans corresponds to multiple teaching arrangements.

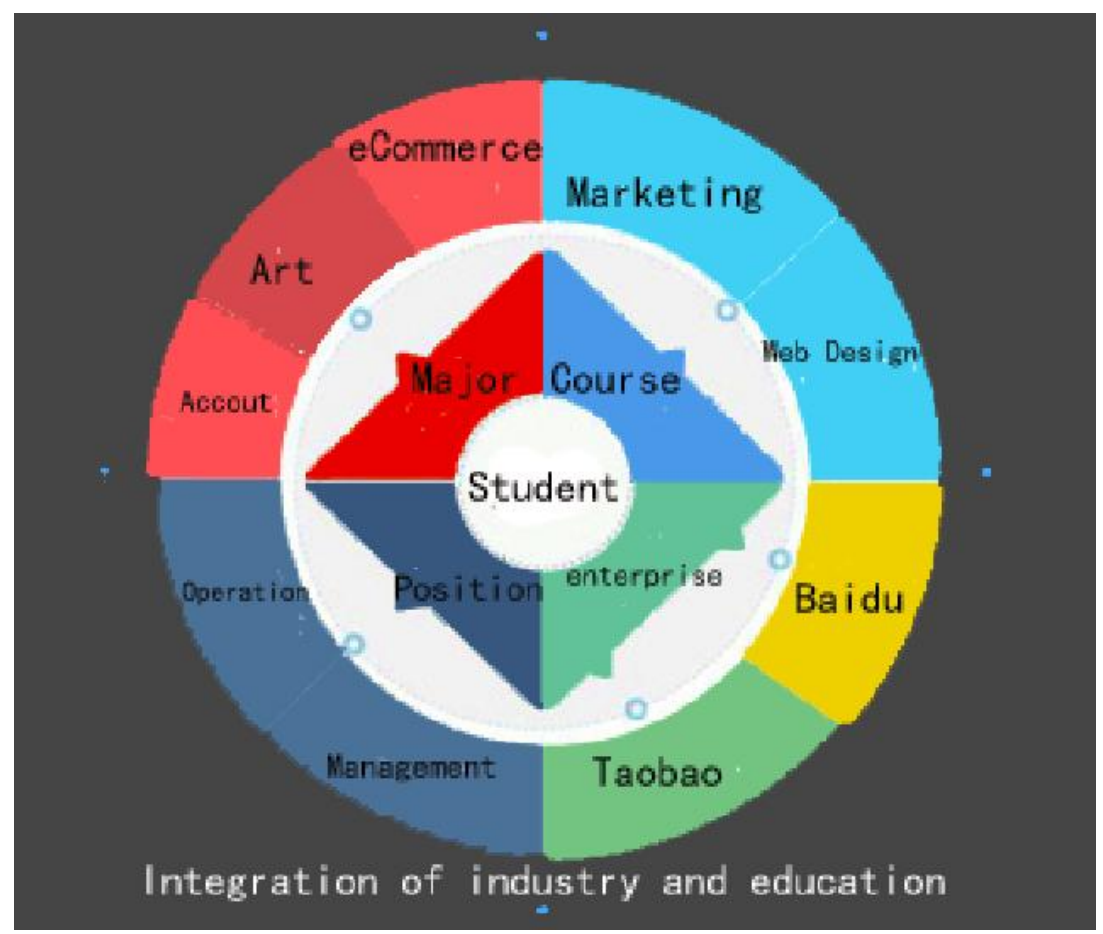

Fig. 1 Integration of industry and education

Six joint. Internet plus college implement six joint of school and enterprise: school and enterprise build joint class for joint training; school and enterprise develop jointly curriculum and teaching materials for joint implementation of teaching; school and enterprise combine teaching management for quality control; school and enterprise jointly set up the training room and network curriculum resources for the construction of teaching resources; schools and enterprises implement assessment of student jointly for inspection of teaching achievements; school and enterprise organize student employment for share the fruits of cooperation.

Four steps. Internet plus college can be built from the following four steps:

To find the value and realize the foothold. Internet plus college controls a common link in many chains for the relative higher efficiency, so that one or more chains can provide more value and build a platform.

To establish core strengths and expand platforms. On the base of platform, internet plus college establish the intangible assets, increase the extension of platform. Under the impetus of the network effect, college make the platform quickly and bigger, in order to realize the greater platform value.

To derive more services to build eco circle. In the establishment of a platform for more links, internet plus college build more efficient auxiliary services, enhance the platform's sticky and competitive barriers, and ultimately form the platform ecosystem.

To upgrade platform strategically and consolidate ecosystem. The value of the ecosystem of the platform changes with the development of the college. The platform ecosystem function is the key to maintain and enhance ecological system. 


\section{Significance}

(1) Internet plus college is conducive to the integration of industry and education. Integration of industry and education is a major initiative to promote the reform and development of higher education, its essence lies in linking closely together of higher education and economic and social development, takes promoting regional economic and social development as the goal, takes talents training and enterprise development as the foothold, gradually realize benign interaction mechanism innovation, including the operation mode, curriculum system and resource integration, in order to cultivate application talents.

(2) Internet plus college is conducive to cultivate innovative talents. For application talents cultivation, practical ability is weak, humanities is shortage, social needs and school culture is not the same specification. Internet plus college can accomplish a "healthy" detection for vocational ability of school talent training, and strive to explore application talents cultivation standards for social recognition and requirements of the development of the industry. That is, the training of the talent pay more attention to social recognition and employment quality.

(3) Internet plus college is conducive to the transformation and development of colleges and universities. Depth integration of industry and education is to promote restructuring and development of colleges and universities, is an important way to further deepen cooperation, both to consolidate the results in the early stage of transformation and development, and pointed out the direction for the development of the next transition, making the transition route of the development of the sustained and healthy development.

\section{Acknowledgment}

This work was supported by Jiangxi Province Office of Education of Humanities and Social Science Research [No. GL 1409]. And the project of Technology Department of Jiangxi Province [No 2013BBE50051] also gives us lots of help.

\section{References}

[1] Yang Z T. The Integration of Industry and Education and its Actual Forms[J]. Journal of Baoji College \& Science, 2001.

[2] Zhang L F, Liu Y C, Liu S Z. Research and Practice of the Talent Training Model for Applied Undergraduate Based on the Integration of Industry,Education and Acadeny - Take Hunan Institate of Engineering as an Example[J]. Journal of Hunan Institute of Engineering, 2010.

[3] Yan-Feng L I, Xue S D, Xiang L, et al. Study on Cultivating Engineering Quality of Young Teachers Through Integration of Industry,Education and Research[J]. Journal of Higher Education in Science \& Technology, 2010.

[4] Li B. Research on Industry Integration and Education of Multi-talented Prospective Employees[J]. Forum on Science \& Technology in China, 2011.

[5] Zhou J G, Guo-Hui H, Cai L W. Combination of Industry and Education,Coordination of School and Enterprise,Integration of Theory and Practice—-Research on Practical Teaching Mode for Integration of Vocational School and Enterprise[J]. Journal of Wuhan Polytechnic, 2010.

[6] Lin Y U, Min X U. Implementing the Tutor System in the Integration of Industry and Education to Promote the Competitiveness of Vocational College Students[J]. Journal of Wenzhou Vocational \& Technical College, 2007. 
[7] Wei H E, Yanwen L I. The Integration Research on the Education Model of the Fusion of Education and Industry of Higher Vocational Education under the Market Economy Background[J]. Modern Education Management, 2014.

[8] Chen G, Qin-Ming H E, Chen Y, et al. Engineering and Compound Oriented Internationalized Computing Talent Training with the Integration of Ind ustry,Education and Research[J]. Computer Education, 2010.

[9] Bai J, Song Y X, Sun H P, et al. Research on Talents-Training Model of the Integration of Education, Research and Industry[J]. Journal of Electrical \& Electronic Education, 2009.

[10] Owusu-Manu D G, Edwards D J, Holt G D, et al. Industry and Higher Education Integration: A Focus on Quantity Surveying Practice.[J]. Industry \& Higher Education, 2014, 28. 